

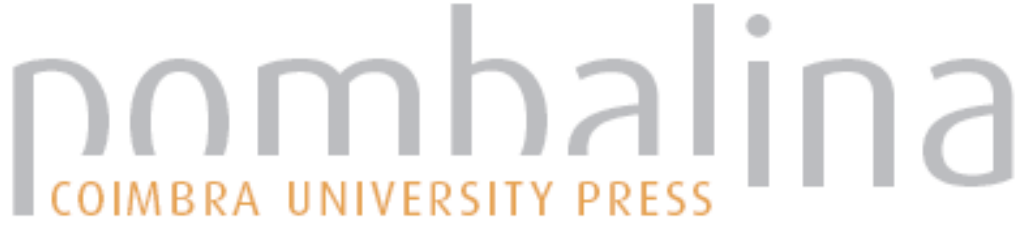

\section{Importância da Medicina Legal em situação de catástrofe: a queda da Ponte Hintze Ribeiro}
Autor(es): $\quad$ Gandra, Sara; Campos, Paulo; Reis, Ana Mafalda; Bandeira, Romero
Publicado por: $\quad \begin{aligned} & \text { Imprensa da Universidade de Coimbra; RISCOS - Associação } \\ & \text { Portuguesa de Riscos, Prevenção e Segurança }\end{aligned}$

URL persistente:

URI:http://hdl.handle.net/10316.2/34959

DOI:

DOI:http://dx.doi.org/10.14195/978-989-96253-3-4_159

Accessed : $\quad$ 26-Apr-2023 15:18:17

A navegação consulta e descarregamento dos títulos inseridos nas Bibliotecas Digitais UC Digitalis, UC Pombalina e UC Impactum, pressupõem a aceitação plena e sem reservas dos Termos e Condições de Uso destas Bibliotecas Digitais, disponíveis em https://digitalis.uc.pt/pt-pt/termos.

Conforme exposto nos referidos Termos e Condições de Uso, o descarregamento de títulos de acesso restrito requer uma licença válida de autorização devendo o utilizador aceder ao(s) documento(s) a partir de um endereço de IP da instituição detentora da supramencionada licença.

Ao utilizador é apenas permitido o descarregamento para uso pessoal, pelo que o emprego do(s) título(s) descarregado(s) para outro fim, designadamente comercial, carece de autorização do respetivo autor ou editor da obra.

Na medida em que todas as obras da UC Digitalis se encontram protegidas pelo Código do Direito de Autor e Direitos Conexos e demais legislação aplicável, toda a cópia, parcial ou total, deste documento, nos casos em que é legalmente admitida, deverá conter ou fazer-se acompanhar por este aviso.

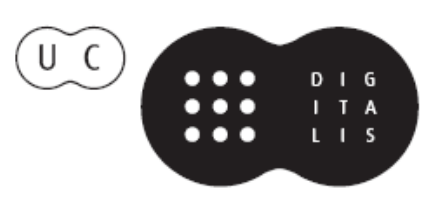



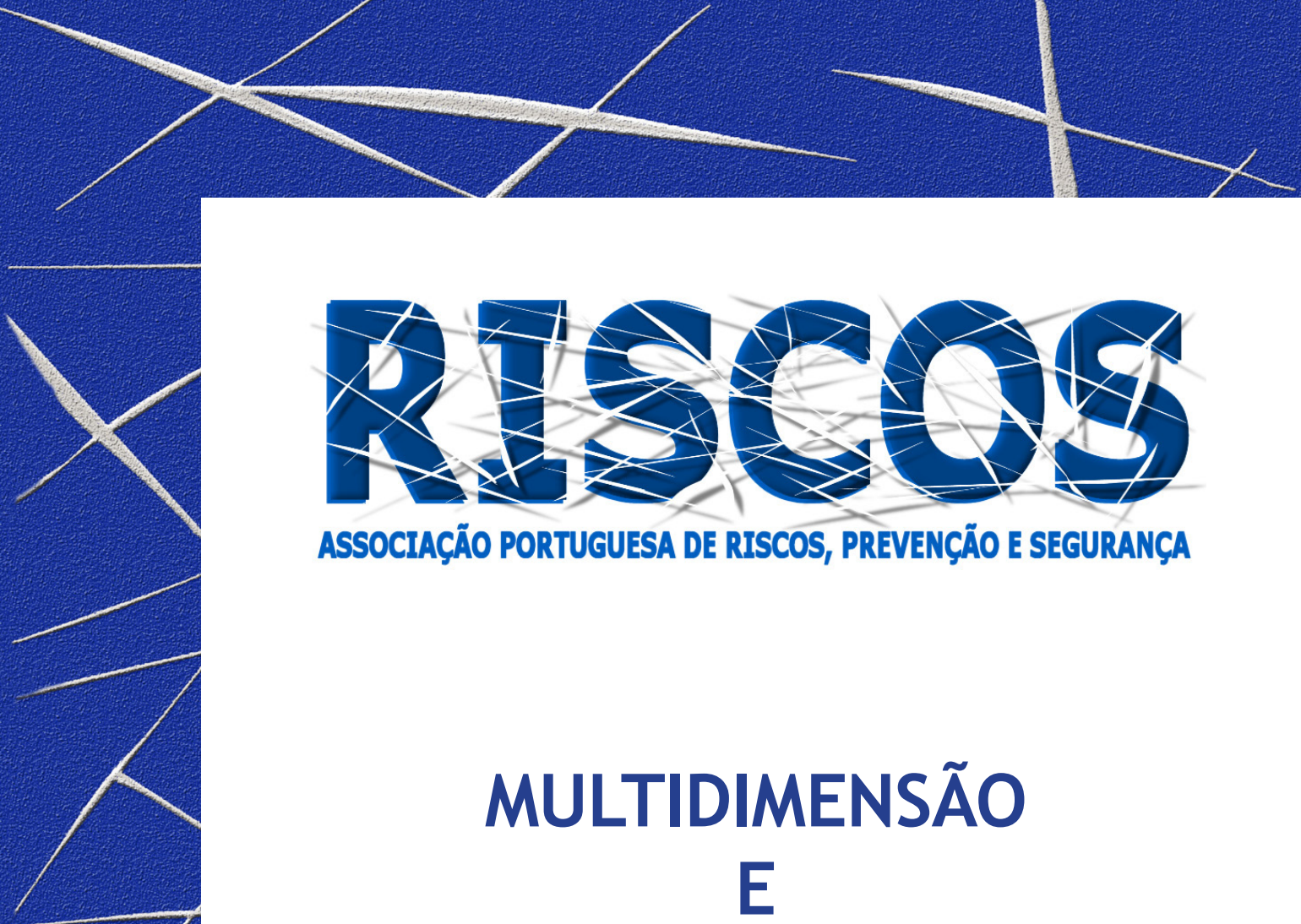

ASSOCIAÇÃO PORTUGUESA DE RISCOS, PREVENCCÃO E SEGURANÇA

MULTIDIMENSÃO

E
TERRITÓRIOS DE RISCO

III Congresso Internacional

I Simpósio Ibero-Americano

VIII Encontro Nacional de Riscos

Guimarães

2014 


\title{
IMPORTÂNCIA DA MEDICINA LEGAL EM SITUAÇÃO DE CATÁSTROFE - A QUEDA DA PONTE HINTZE RIBEIRO
}

\author{
Sara Gandra \\ Instituto de Ciências Biomédicas Abel Salazar, Universidade do Porto \\ saragandra@gmail.com \\ Paulo Campos \\ Instituto de Ciências Biomédicas Abel Salazar, Universidade do Porto \\ pacampos@netcabo.pt / paulocampos@inem.pt \\ Ana Mafalda Reis \\ Instituto de Ciências Biomédicas Abel Salazar, Universidade do Porto \\ docmaf@sapo.pt \\ Romero Bandeira \\ Instituto de Ciências Biomédicas Abel Salazar, Universidade do Porto \\ hmedcat@icbas.up.pt
}

\begin{abstract}
RESUMO
Como processo de ruptura e desarmonia entre o ambiente natural e o sistema social, a catástrofe é um acontecimento súbito e quase sempre imprevisível. De carácter natural ou fruto da inventiva humana é responsável por provocar inúmeras vítimas bem como danos materiais avultados. Tem a capacidade de abalar gravemente o indivíduo como ser holístico, bem como a vida das populações e o tecido social e económico da zona onde surge.

As catástrofes podem ser definidas e conceptualizadas das mais variadas formas, dependendo das suas próprias características e do autor que as classifica.

A conceptualização da catástrofe tem que ver com a desproporcionalidade entre recursos humanos e materiais de socorro e o número de vítimas a socorrer.

A análise do domínio de acção das forças de socorro e segurança permite ressalvar a importância do contacto entre as equipas intervenientes e a articulação e funcionamento das diversas entidades para que os recursos disponíveis possam ser optimizados, por forma a prestar socorro célere e eficaz.

É imperativo o estabelecimento de acções de planeamento, prevenção e exercício, com base no levantamento de vulnerabilidades e no estabelecimento de mapas de risco, de forma a exercitar e testar equipas, instituições e organismos intervenientes, à luz do que se tem feito a nível internacional.

A Medicina Legal e o seu extenso raio de influência, quer seja no estabelecimento da causa e mecanismo de morte e da extinção da personalidade através da realização das autópsias médico-legais, devolvendo por fim os corpos às famílias, quer através da organização e coordenação das equipas médico-legais face à ocorrência da situação de catástrofe propondo medidas de cooperação, ligação, assistência e propagação da informação entre serviços e entidades que prestem assistência e socorro bem como a elaboração de planos e medidas preventivas de protecção de pessoas e bens, com base no estudo do quadro traumatológico que as vítimas apresentam, tornam- na indissociável da Medicina de Catástrofe. Desta forma,

1. Através da reconstituição de uma situação catastrófica ocorrida no nosso tecido territorial foi possível reflectir e analisar uma situação real e estabelecer um paralelismo entre o ocorrido e as medidas tomadas bem como recursos humanos e técnicos utilizados numa situação de tal envergadura.

2. A Medicina de Catástrofe, como teia situacional que é, articula-se em pleno com a Medicina Legal, sendo que esta é a aplicação do conhecimento científico e biomédico às questões do direito.

3. Através dos capítulos em que a Medicina Legal desenvolve a sua actuação se prova a necessidade de uma equipa multidisciplinar, especialista e experiente.
\end{abstract}

Palavras-chave: Catástrofe, Medicina de Catástrofe, Medicina Legal, socorro a Multivítimas 


\section{Introdução}

A Medicina de Catástrofe, como especialidade com acção pluridisciplinar, nasce da necessidade de minimizar a desproporcionalidade entre vítimas que necessitam de assistência e apoio e os recursos humanos e técnicos disponíveis.

É a medicina dos "desastres de massas", dos cataclismos e das perdas incomensuráveis. É a medicina da urgência individual transformada em colectiva, com acção multifacetada, que encerra em si todos os conhecimentos de índole médica e do domínio científico, bem como todos os conhecimentos da mais diversa ordem que em sinergismo visam devolver o equilíbrio àqueles que foram vítimas do acontecimento catastrófico.

O Mundo tem vindo a ser assolado pelos mais variados acidentes catastróficos decorrentes dos constantes avanços tecnológicos, dos condicionalismos sócio-culturais, do desequilíbrio social, do avanço desmedido dos grandes complexos industriais e habitacionais. A convivência humana em grandes edificações, as migrações, o melhoramento das vias de circulação de tráfego, o aumento dos actos terroristas e de acções bélicas a par da ausência de meios de prevenção e predição são factores que se nos afiguram como propiciadores de catástrofes da mais diversa etiologia.

O profundo interesse nesta área deve-se ao facto de ser um ramo da Medicina ainda pouco explorado e sobre o qual pouco se tem dito, escrito e feito no nosso país, que pelas suas condições geográficas, meteorológicas, estruturais e estratégicas tem todas as características para que possa ser assolado por uma catástrofe major que afecte e assole a sua integridade. A dificuldade major de actuação prende-se com o carácter não programável, dificilmente preditível e com um poder de aniquilação incomensurável sendo que na maioria das vezes pelas suas características sui generis não pode ser extrapolada para outras situações catastróficas. Através da reconstituição da queda da Ponte Hintze Ribeiro e consequente socorro foi possível reflectir e analisar uma situação real e estabelecer um paralelismo entre o ocorrido e as medidas tomadas, bem como recursos humanos e técnicos utilizados numa situação de tal envergadura. Às 21 horas e 10 minutos do dia 4 de Março de 2001, domingo, numa noite de Inverno precedida e antecedida por tantas outras igualmente chuvosas, a parte central do tabuleiro da ponte Hintze Ribeiro caiu, arrastando um autocarro de passageiros e dois automóveis para as águas do Rio Douro. Uma excursão às amendoeiras em flor, em Trás-os-Montes, terminou em tragédia, à porta de casa.

Grande parte das vítimas da derrocada da ponte que ligava Entre-os-Rios a Castelo de Paiva residia na freguesia de Raiva.

São 17000 os habitantes do concelho com pouco mais de $100 \mathrm{Km}$ quadrados e nove freguesias, 6 das quais ribeirinhas.

A Medicina de Catástrofe, como teia situacional que é, articula-se em pleno com a Medicina Legal, sendo que esta é a aplicação do conhecimento científico e biomédico às questões do direito. Através dos capítulos em que a Medicina Legal desenvolve a sua actuação se prova a necessidade de uma equipa multidisciplinar, especialista e experiente.

Indubitavelmente, as situações de catástrofe surgem e evoluem a par da aniquilação de vidas e bens, pelo que além da necessidade óbvia de um socorro célere e efectivo é imperioso solucionar uma pluralidade de questões médico-legais, identificação dos mortos e do estabelecimento da causa e mecanismo da morte, uma vez que através da análise de algumas situações de catástrofe, se pode constatar que o número de vítimas decorrentes das catástrofes naturais entre 1947 e 1970, a nível mundial, foi calculado em cerca de 1.200.000. (Bandeira 2008). 
Toda esta mudança, encarada segundo um modelo antropocêntrico e sociocêntrico relaciona-se profundamente com a Medicina Legal, como uma ciência complexa que encerra em si múltiplos ramos do saber e como "ponte que é entre a medicina e o direito, cabe-lhe a análise científica das questões para proporcionar um equilíbrio desejável entre ambos, com mira na dignidade do Homem como ser superior" (J.E. Pinto da Costa 2004)

O relacionamento entre ambas é potenciado aquando do surgimento da situação catastrófica. Com o intuito de tornar esta ligação mais visível, foi abordada uma situação acontecida e amplamente difundida no nosso país - a queda da ponte Hintze Ribeiro - que se traduziu por profundas repercussões quer a nível regional, quer a nível nacional afectando a integridade do país no seu plano sócio-político, cultural e médico-legal.

\section{Conclusão}

A ocorrência de uma catástrofe encerra em si uma pluralidade de efeitos nefastos e repercussões a diversos níveis. Tem a capacidade de afectar o indivíduo e a sociedade em todas as suas dimensões e ser de uma complexidade tal que a solução dos efeitos produzidos passa pela articulação dos serviços disponíveis a nível local, municipal, nacional ou sectorial para que se proceda ao melhor aproveitamento possível dos recursos.

As inúmeras relações que a Medicina de Catástrofe e a Medicina Legal estabelecem com outros ramos da ciência e o seu extenso raio de influência tornam-nas indissociáveis;

Os acidentes catastróficos de índole natural ou fruto da inventiva humana condicionam o surgimento de um sem número de vítimas pelo que todo o processo médico-legal identificativo pressupõe a existência de uma equipa multidisciplinar e especializada, fundamental num cenário de catástrofe;

Relativamente à sociedade, a Medicina Legal tem como competências a resolução de questões relacionadas com indemnizações, heranças, determinação do estado civil do cônjuge sobrevivente, atribuição de prémios de apólices e obtenção de benefícios sociais, bem como a identificação antropológica das vítimas, a identificação cronológica do acidente e determinação cronológica da morte e o estabelecimento do mecanismo e causa de morte, comprovando a extinção da personalidade através da realização das autópsias médico-legais, devolvendo por fim os corpos às famílias é seu papel preponderante.

A Medicina de Catástrofe, como teia situacional que é, articula-se em pleno com a Medicina Legal, sendo que esta é a aplicação do conhecimento científico e biomédico às questões do direito.

\section{Bibliografia}

ANGELINI F (1989) La Ètica en La Medicina de Desastres. Dolentium Hominum 11: 62 - 64

BANDEIRA R (1995) Medicina de Catástrofe - da exemplificação histórica à latroética: Instituto de Ciências Biomédicas Abel Salazar - Universidade do Porto, Dissertação de Doutoramento

CALDAS I; AFONSO A; MAGALHÃES T (2002) Identificação humana com recurso a técnicas de identificação dentárias em situação de catástrofe, Revista Portuguesa de Estomatologia, Medicina Dentária e Cirurgia Maxilo- Facial 3: 16- 19

CENTRO NACIONAL DE PREVENCIÓN DE DAÑOS Y PERDIDOS (1988) El comportamiento de las personas en situaciones de emergência- Cepreven Editora - Asociácion de investigation para la seguridad de vidas e bienes, Madrid

COURBILL J; BUFFAT J; CHABANNE JP; CHEVALIER F; DORNE R; NOTO R; PAILLER J L; VIDELAINE J (1987) Medicine en Situación de Catastrophe, Massan, Paris 
DIRECCIÓN GENERAL DE PROTECCIÓN CIVIL DE ESPAÑA - Cruz Roja (2001) Recomendaciones para situaciones de emergencia colectiva, Madrid

EMMANUELLI J; EMMANUELLI X (1995) Au secours de la vie - La Médecine d' Urgence, Découvertes Gallimard Sciences, Paris

EQUIPA MÉDICO- LEGAL DE INTERVENÇÃO EM DESASTRES DE MASSA (2002), Instituto Nacional de Medicina Legal

EZEQUIELA; VIEIRAA (2002) Missão em Castelo de Paiva - Relato de um participante nas operações de resgate, $2^{\text {a }}$ ed., Editorial Caminha, Lisboa

FAVRE R (1992) L'Homme et les Catastrophes, $2^{\mathrm{a}}$ ed., Vol. I, Èditions France- Seléction, Paris

FERNANDES R (2003) Procedimentos no Plano de Emergência, Revista da Escola Nacional de Bombeiros, 25: 38- 41

FRANÇA G (2004) Medicina Legal, $7^{\text {a }}$ ed, Guanabara Koogan, Rio de Janeiro

GOIRICELAYA E (1998) Desastres y medios de comunicación, Asociacion Profesional de Tecnicos de Bomberos, Emergência 112, Gallarta

GUNN S (1992) Le Medecin et les catastrophes, Revue de L'Amelisap 13 :20- 23

LARCAN A (1988) La Medicine de Catastrophes. La Revue du Practicien 38, 11: 645- 647

REBELO F (2003) Revista de Geografia Física Aplicada no Ordenamento do Território e Gestão de Riscos Naturais e Territoriais, Minerva, Coimbra

REBELO F (2003) Riscos naturais e acção antrópica - estudos e reflexões, $2^{\mathrm{a}}$ ed., Imprensa da Universidade, Coimbra

RIBEIRO P (2003) Os Centros de Coordenação de Socorros, Revista da Escola Nacional de Bombeiros, 25: 10- 12 ROCHA F (2003) O papel da sociedade no planeamento de emergência, Revista da Escola Nacional de Bombeiros 25: 28- 30

SALAZAR-GALHARDO A (2002) A Ponte caiu-me em cima - a tragédia de Entre-os-Rios, $1^{\text {a }}$ ed., Notícias Editorial, Lisboa

STONE D; ARMSTRONG R; MACRINA D; PANKAU J (1999) Introdução à Epidemiologia, Mac Graw-Hill, Brasil. 